\title{
ON DILATATION OF THE BLADDER AND URETERS IN CHILDHOOD
}

BY

F. J. POYNTON, M.D., F.R.C.P., Physician to Hospital for Sick Children, Great Ormond Street, Physician to University College Hospital, London,

and

W. P. H. SHELDON, M.D., M.R.C.P.,

Medical Registrar, Hospital for Sick Children, Great Ormond Street, London.

The purpose of this communication is to consider some of the conditions which may give rise during childhood to dilatation and hypertrophy of the bladder and ureters. Many instances of this nature have been already described and in some of these there has been an obviously demonstrable cause in the nature of some form of severe obstruction in the urinary tract; but in others post-mortem examination has revealed no organic obstruction, and for such various theoretical explanations have been suggested. These relatively rare conditions have recently been brought to our notice by the investigations carried out on five children under our care in the Hospital for Sick Children, Great Ormond Street, who presented symptoms either of intractable enuresis or of chronic infection of the urinary tract. In addition the opportunity has arisen of examining three cases post mortem : a study of these forms the basis of this paper.

CASE 1. W. B., a boy, aged 6 years, was admitted to hospital, December 1922, with a history of enuresis since birth. It was at once apparent that the condition was unusual for there was enuresis by day as well as by night, and yet the bladder was so distended as to reach the level of the umbilicus. No obstruction was offered to the passage of a catheter although the condition was clearly one of retention of urine with overflow incontinence.

This boy suffered from great thirst and had frequent headaches. The urine was alkaline, with an S.G. of 1006, and pus and a cloud of albumen were present; sugar and ketone bodies were absent. The right kidney was easily felt. The blood urea was $114 \mathrm{mgm}$. per 100 c.c. (Dr. Harrison); systolic blood pressure $135 \mathrm{~mm}$. Electrical treatment was tried, and this with urinary antiseptics improved the condition to some extent, and he left hospital but only to return later with a recurrence. Uræmic symptoms were now more obvious and steps were taken by Mr. O. Addison to obtain a more accurate diagnosis by pyelography. This showed a greatly dilated bladder and a tortuous left ureter with considerable distension of the renal pelvis. Shortly after this examination the boy died in uræmic coma. Unfortunately a postmortem examination was refused.

It was this case which first drew our attention to the combination of painless enuresis with a distended bladder. In the light of later cases, it is very probable that had the boy lived long enough for a pyelogram of the right side to be taken, this ureter would also have been shown to be dilated. 
The radiogram by Dr. Bertram Shires shows the condition that was present in the last period of the boy's life (Fig. 1).

CASE 2. T. G., a girl, aged 10 years, was admitted to hospital, April 1923, for abdominal pain and vomiting. There was a history of scarlet fever at two years of age. The patient was a well nourished child, the heart was normal, systolic blood pressure $100 \mathrm{~mm}$. There was no fever, and neither kidney was palpable; the bladder was full and the urine always contained pus and albumen; S.G. 1010; on culture bacillus coli was isolated. Wassermann reaction negative. Blood urea $45 \mathrm{mgm}$. per 100 c.c.

The urea concentration test showed :-

\begin{tabular}{|c|c|c|c|c|c|c|}
\hline \multicolumn{2}{|c|}{ Before urea 6 a.m. } & .. & -. & . & $\cdots$ & $1.45 \%$ \\
\hline After urea & 7 a.m. & .. & . & $\cdots$ & . & 1.18 \\
\hline & 8 a.m. & . & . & . & . & $1.40^{\circ}$ \\
\hline & 9 s.m. & .. & .. & $\ldots$ & $\ldots$ & 1.45 \\
\hline
\end{tabular}

Mr. O. Addison examined with the cystoscope and found the bladder large, easily holding seven ounces. The average daily output of urine was $25-30$ ounces. There was some basal cystitis, with much trabeculation and sacculation. Pyelography showed considerable dilatation of both ureters (Fig. 2).

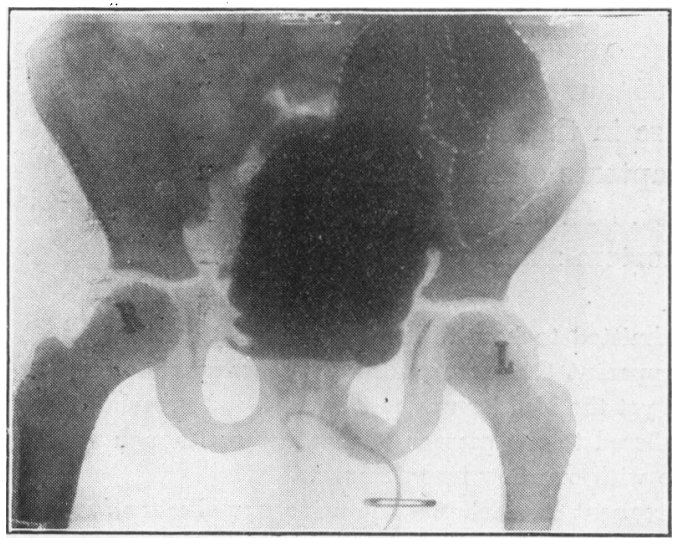

Fig. 1. Radiogram of Case 1 showing bladder and tortuous left ureter filled with solution of Sodium Bromide.

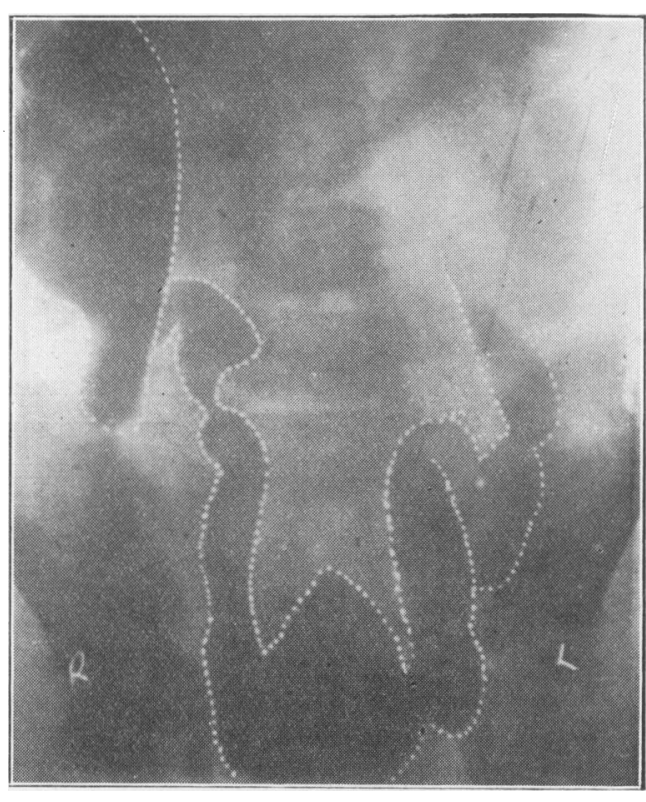

Fig. 2. Radiogram of Case 2. showing both ureters dilated and tortuous; the pelvis of the right kidney can be seen to be very dilated.

Seen three years later she had been in fair nealth, but suffered from constant thirst and was troubled by headaches and nocturnal frequency. There was a little puffiness under her eyes. The heart's action was forcible, and the cardiac dulness extended half a finger's breadth beyond the left nipple; systolic blood pressure $130 \mathrm{~mm}$. The right kidney was just palpable. The uirine was albuminous and contained much pus; blood urea was now $128 \mathrm{mgm}$. per 100 c.c. The patient is still under observation.

CASE 3. S. W., a boy, aged 2 years and 10 months, was admitted to hospital in January, 1926, for wasting, $\mathrm{H}$ e had always been delicate and continually complained of thirst. On 


\section{DILATATION OF BLADDER AND URETERS}

admission the bladder was found reaching up to the umbilicus, and there was constant enuresis ; the urine was acid, contained a cloud of albumin and much pus, and on culture grew bacillus coli. Blood urea $104 \mathrm{mgm}$. per 100 c.c.

Experience of the former case of this type led to cystoscopic examination of the bladder ; the bladder was distended, sacculated and trabeculated, and there was evidence of chronic cystitis ; the ureteric orifices were normal. Under the anæsthetic the right ureter was palpable but neither kidney was felt. Pyelography was not attempted. As there seemed some slight obstruction at the level of the triangular ligament bougies were passed daily in sizes increasing from 6-10 to 10-14 and electrical treatment also employed.

In spite of treatment the bladder remained distended and the patient was discharged after 3 months in much the same condition as on admission. He is still under observation and the bladder has usually been found distended.

C'ASE 4. F. M., a female child, aged 3 years, was admitted to the hospital in February, 1925, with a history of seven weeks' fever with rigors and occasional vomiting. Previously to this she had been healthy and there was no history of enuresis. On the discovery of pus and albumen and bacillus coli in the urine, the diagnosis of acute pyelitis was made. Improving under medicinal treatment she was discharged, but was again admitted in June, 1925, for a relapse with pus and albumen in the urine. This time she was treated with an autogenous vaccine and again improved, but the urine still contained a few pus cells. Again there was no history of enuresis. She was admitted a third time in June, 1926, and treated with citrate of potash and later with hexyl-resorcinol but recovery was only imperfect.

Re-admitted a fourth time in September, 1926, under Mr. O. Addison, cystoscopy showed a slight general cystitis. Pyelography showed the left kidney and ureter to be normal, but the right ureter was extremely dilated with a kink at the upper end. The renal pelvis was large but the calyces were apparently normal. Urine from the left kidney contained urea $0.7 \%$, a few red corpus les but no casts; from the right, urea $0.5 \%$, albumen, pus and tubular

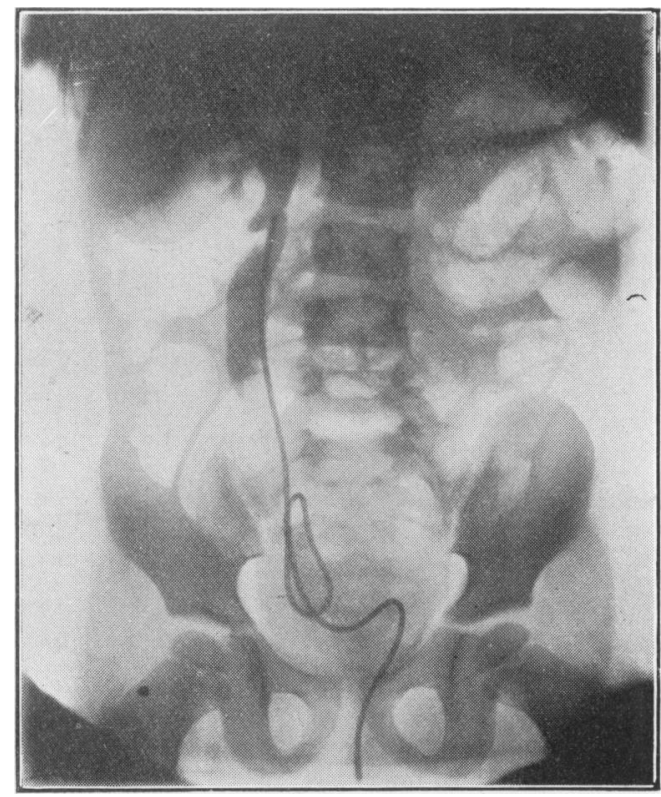

Fig. 3. Radiogram of Case 4 showing a catheter passed up the right ureter. The top of the catheter has reached a kink in the ureter. 
casts, and from this the bacillus coli was grown. An X-ray examination of the urinary tract for calculus was negative. The radiogram by Dr. Bertram Shires shows the condition presented. (Fig. 3.)

CASE 5. I. M., a female child, aged $6 \frac{1}{2}$ years. In June, 1925, there was a history of an acute illness with fever and vomiting, and a diagnosis was made of acute pyelitis due to the bacillus coli. She was treated with a course of vaccines from July to November, 1925.

She was admitted to hospital in August, 1926, for losing weight since a febrile attack, and was found to have pus and albumen in the urine. The heart was normal ; systolic blood pressure $115 \mathrm{~mm}$. The right kidney was palpable and freely movable. The urine was pale, S.G. 1010, and contained pus and albumen, but no blood or casts. B. coli was isolated. Blood urea 42 mgm. per 100 c.c.

Urea concentration test :-

$$
\begin{array}{rrrrrr}
\text { Before urea } \quad . & \ldots & \ldots & \ldots & \ldots & 2.11 \% \\
\text { After urea } 1 \text { hour } & \ldots & \ldots & \ldots & \ldots & 1.78 \% \\
2 \text { hours } & \ldots & \ldots & \ldots & \ldots & 2.39 \% \\
\text { 3 hours } & \ldots & \ldots & \ldots & . & 2.27 \%
\end{array}
$$

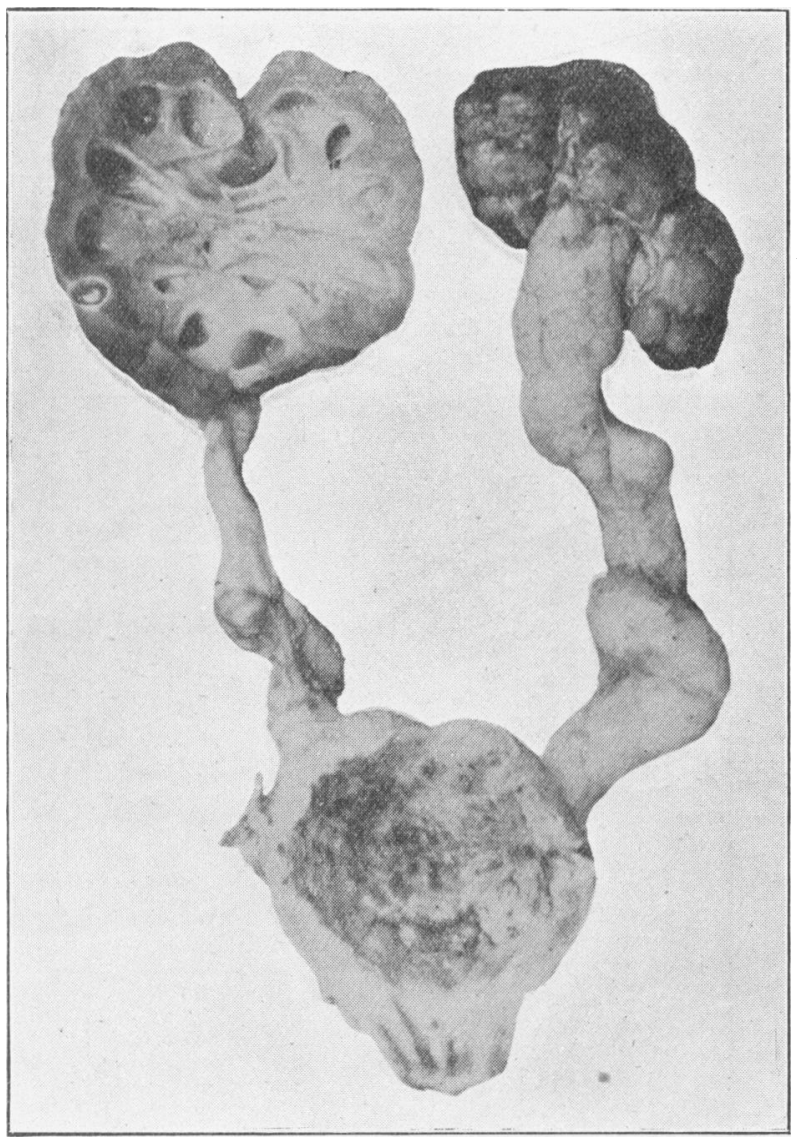

Fig. 4. Photograph taken at the post-mortem examination of Case 6 showing hypertrophy of the bladder and dilatation of the ureters. The urethra has been divided just distal to the veru montanum. 


\section{DILATATION OF BLADDER AND URETERS}

Cystoscopy showed the left ureteric orifice large, gaping and motionless. The right also large and drawn out. There was no inflammation.

CASE 6. For this case we are indebted to Mr. Tyrrell Gray. J. C. W., a boy, aged 15 months, was admitted on June 15th, 1926, and died three days later. There had been a history of incontinence of urine for about eight months. He was the elder of two boys, the younger being healthy. There was no history of miscarriages. The infant was very ill, grey and dyspno'ic, with signs of bronchopneumonia. The urine was alkaline, and contained much albumen and pus; on culture a micrococcus of the fæcalis alkaligenes group was isolated. The kidneys were not palpable. Death rapidly followed from bronchopneumonia. Post-mortem examination showed considerable thickening and sacculation of the bladder, and bilateral dilatation of the ureters with hydronephrosis; microscopically the kidneys showed some degree of chronic interstitial nephritis. At the autopsy the urethra was divided immediately distal to the veru montanum and a probe passed along the penile urethra met with no obstruction. The penile urethra was not, however, opened.

The photograph reproduces the condition post mortem (Fig. 4).

CASE 7. For this case we are indebted to Dr. Hutchison. A male child, aged 2 years, was admitted on February 24th, 1927, and died a month later. Since nine months old he had passed urine in a constant dribble both by day and by night, and throughout this period had been excessively thirsty; for the last year he had slowly lost flesh and for the last three weeks had suffered from persistent vomiting.

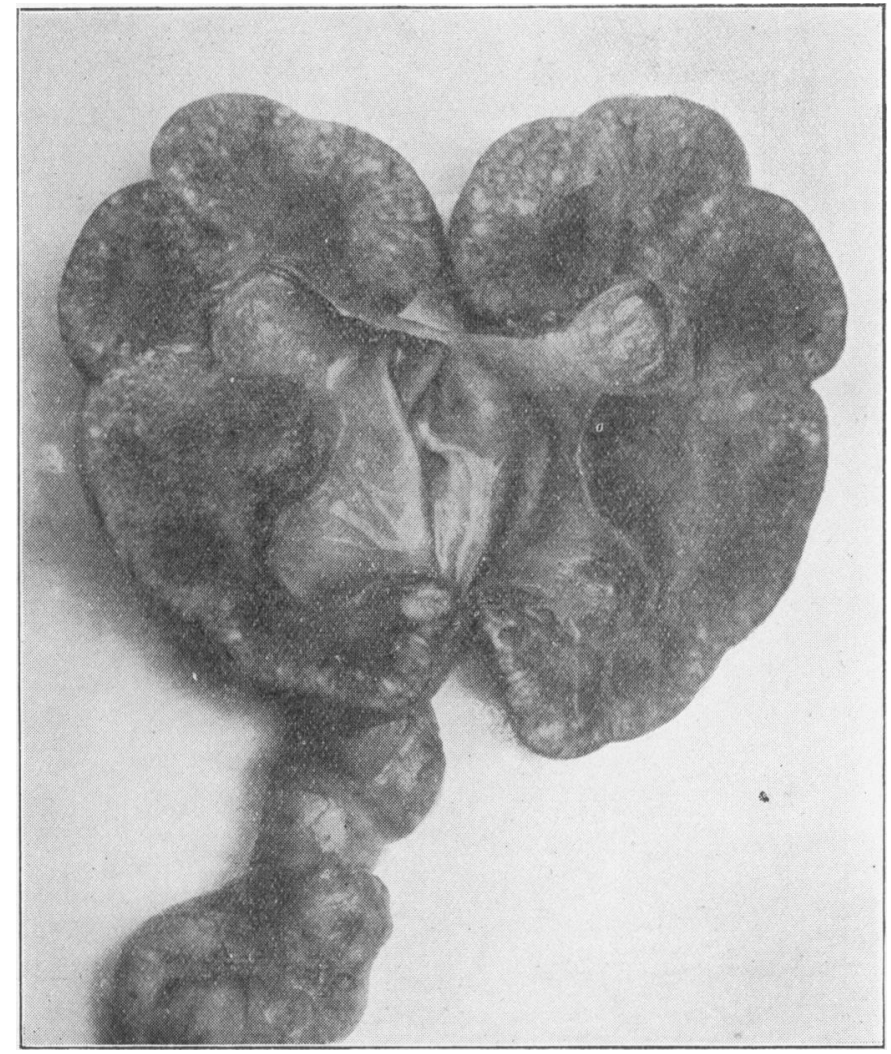

Fig 5. From Case 7 showing the final state of the kidney. The cortex is riddled with small abscesses, a condition of suppurative pyelonephritis. 
On admission, the child was pale and undersized, weight $16 \mathrm{lbs}$. The abdomen was distended, and on palpation the bladder could always be felt, generally reaching up to the level of the umbilicus. Urine constantly dribbled away so that it was found impossible to keep the bed dry. The urine was pale, specific gravity 1010, containing a trace of albumen and some pus; there were no casts or red blood cells. The bony changes associated with renal infantilism were not present. The heart was normal in size ; systolic blood pressure 90-95 $\mathrm{mm}$.

Chemical analysis of the blood by Dr. G. A. Harrison, gave urea $109 \mathrm{mgm}$. per 100 c.c., phosphorus (inorganic) $11 \mathrm{mgm}$. per 100 c.c., calcium $7.8 \mathrm{mgm}$. per 100 c.c. The urea concentration in the urine after 6 grammes of urea only reached $0.95 \%$. The Wassermann reaction was negative.

From the time of admission until death the boy was in a condition of chronic uræmia. He took no interest in his toys or surroundings, but lay very listless and drowsy. All his movements were accompanied by a fine uræmic tremor; vomiting was a symptom during the last week, when his tongue became very dirty and his lips were cracked and ulcerated. Death eventually resulted from uræmia.

At the post-mortem examination, apart from the urinary apparatus the body was normal. The kidneys were both swollen, and were riddled with small abscessee (Fig. 5); on the surface

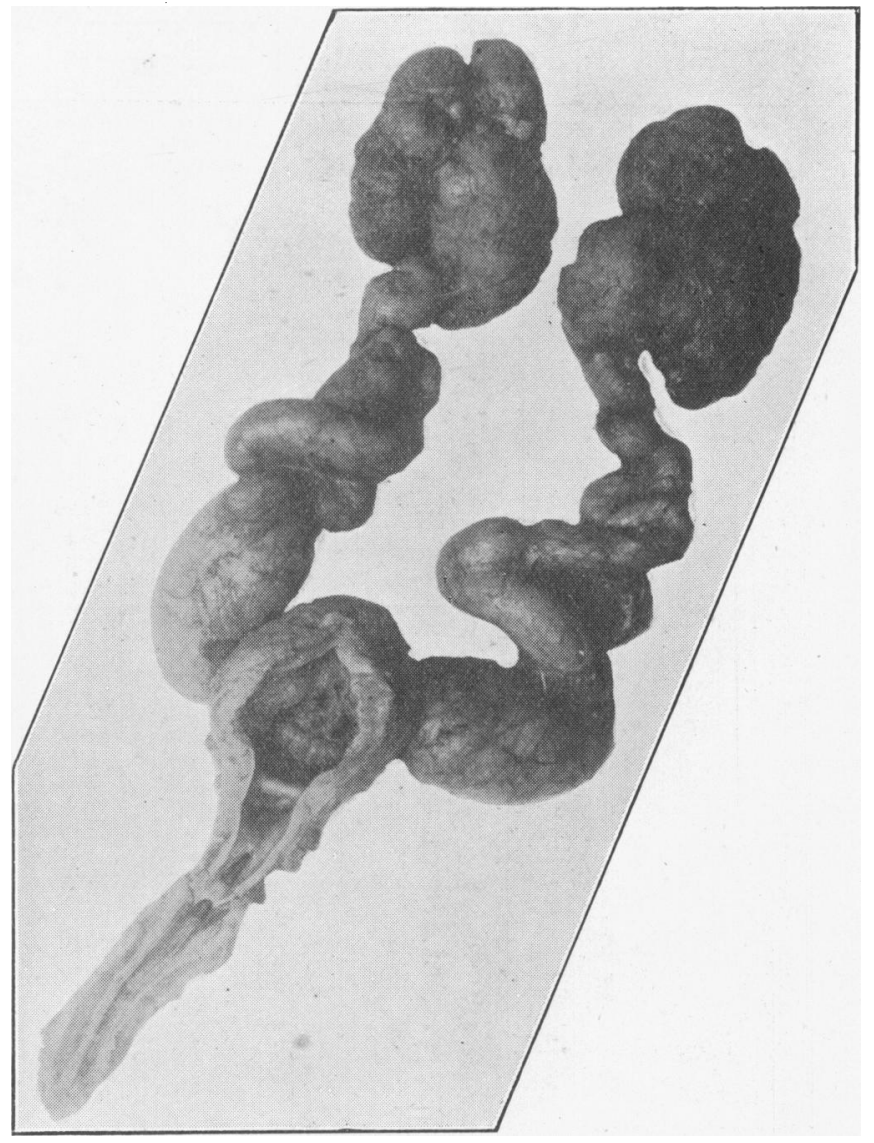

Fig. 6. Showing the whole urinary tract of Case 7. A dark probe has been passed beneath the valve in the posterior urethra. 
of the kidneys were several small cysts, and the renal capsules were adherent in places. Microscopically, in addition to the abscesses, the kidneys showed some increase of interstitial tissue. Both renal pelves and their calyces were dilated, and contained urine turbid with pus. The ureters were both dilated and tortuous, the dilatation becoming more marked towards their lower ends. The ureteric orifices were normal. The bladder showed considerable hypertrophy of its musculature; although the vesical sphincter was quite prominent it did not appear to be more hypertrophied than the rest of the bladder. There were several petechial hæmorrhages under the mucosa of the bladder, the result of an acute cystitis. The prostatic urethra was considerably dilated, but beyond the level of the membranous portion, the urethra was normal.

The cause of the dilatation of the whole urinary tract behind the membranous urethra was found to be a valve-like structure formed by two folds of mucosa, which, taking origin from the distal end of the verumontanum swept round the sides of the urethra to fuse at the roof. From their line of fusion, there hung down a valve-like curtain of mucosa into the lumen of the urethra. The free edge of this valve was directed slightly towards the bladder, and offered an obvious obstruction to the outflow or urine (Figs. 6 and 7 ).

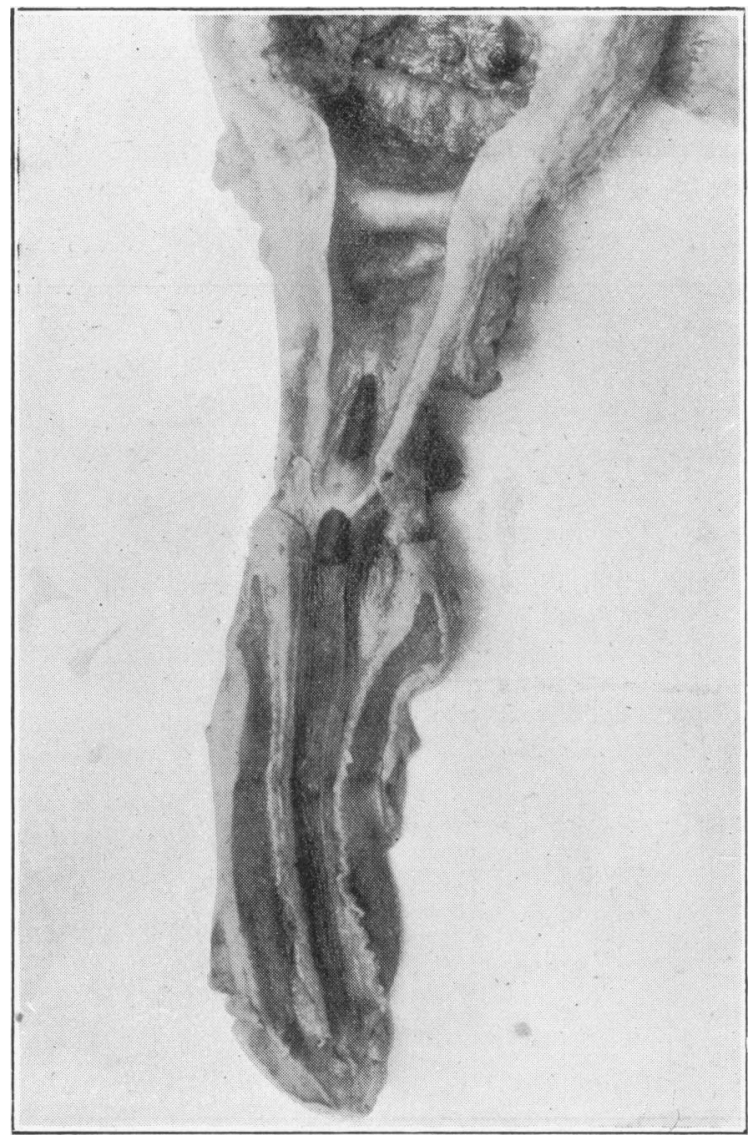

Fig. 7. Shows a larger view of the urethral valve (Case 7) with the probe in position beneath the valve. Note the thickness of the bladder nusculature. 
CASE 8. For this case we are indebted to Dr. Frew. A male child, aged 4 months, was admitted on March 24th, 1927, and died two days later. The child was brought to hospital for vomiting of two days' duration. He was the fourth child of a healthy family, and had previously been normal.

On admission the infant was pale and looked very ill. The urine was turbid and contained a heavy cloud of albumen, and microscopically was found to be crowded with pus cells. An X-ray photograph of the urinary tract showed nothing abnormal. The blood urea was $84 \mathrm{mgm}$. per 100 c.c. Treatment with potassium citrate was commenced, but on the day after admission the child had two convulsions, and died on the following day.

At the post-mortem examination, apart from the urinary tract the body was normal. The right kidney and right ureter were normal, and the ureteric orifices when viewed from the bladder appeared normal. The right ureteric orifice easily admitted a small probe, and urine could be expressed from the right ureter into the bladder. It was, however, found impossible to pass a probe from the bladder into the left ureter, nor could urine be squeezed into the bladder from the left ureter. The nature of the obstruction to the left ureter was only found after a careful dissection of the parts, when a narrow channel nearly half an inch in length was discovered leading from the dilated portion of the left ureter down to the ureteric orifice. This channel represented the terminal portion of the left ureter, and its lumen was too small to admit anything larger than a fine bristle.

The photograph shows the condition present (Fig. 8).

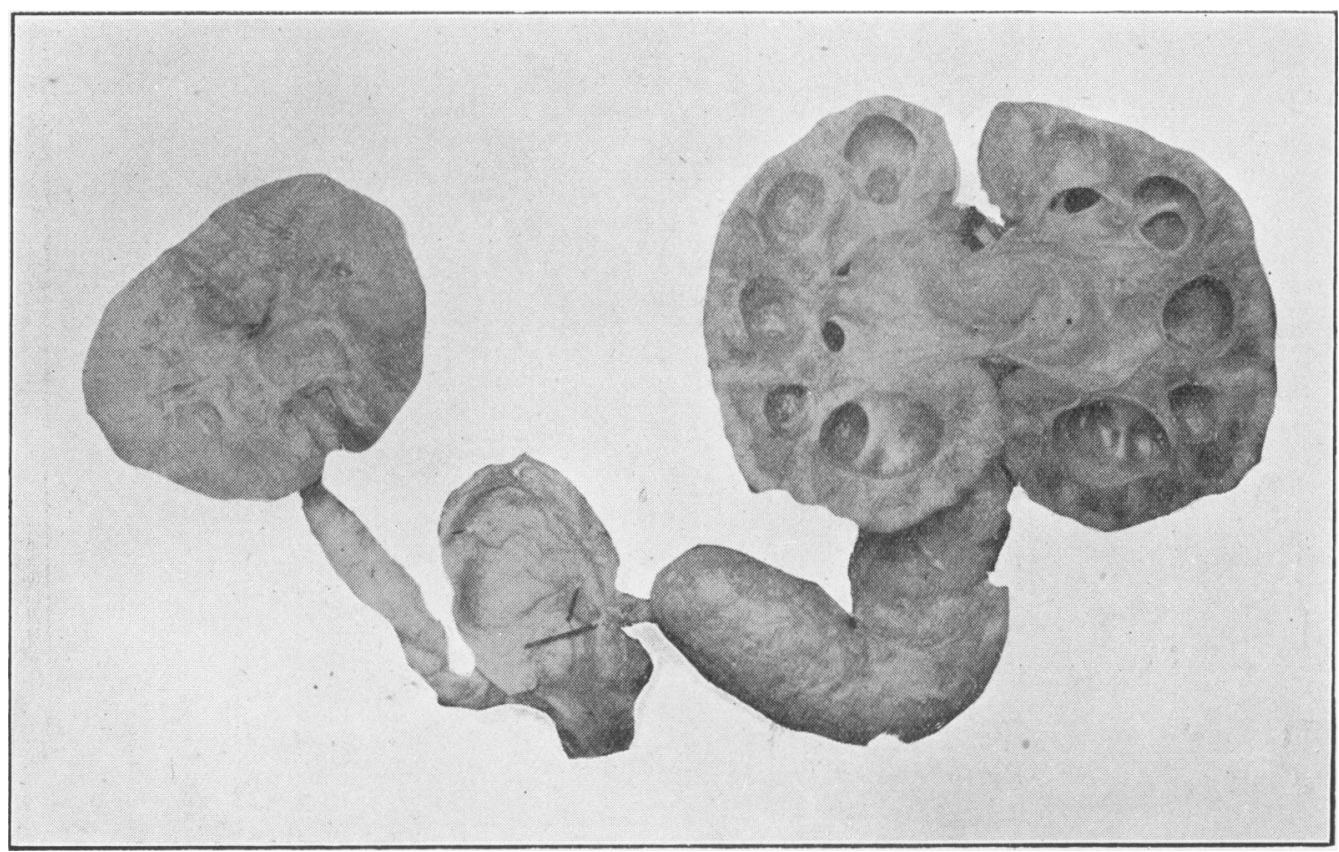

Fig. 8. Showing the condition present in Case 8. The left ureter is very dilated, except for the narrow terminal portion close to the bladder. Bristles have keen passed through the ureteral orifices from the bladder. 


\section{Claassification and Discussion.}

The various pathological conditions in the preceding eight cases led us to investigate the post-mortem records of the Hospital for Sick Children, and in these were found twenty-four instances of dilatation of one or both ureters, associated in four cases with hypertrophy and dilatation of the bladder. Study of their clinical symptoms and correlation of them with the post-mortem findings, together with a reference to the cases reported in the literature, showed that the subject could be simplified by dividing the cases into four groups according to the gross pathological condition present and whether or not the cause was determinable.

Group 1. Hypertrophy and dilatation of the bladder with dilatation of both ureters resulting from some obvious obstruction in the bladder or urethra.

Group 2. Hypertrophy and dilatation of the bladder with dilatation of both ureters, but without any obvious obstruction.

Group 3. A normal bladder with dilatation of one or both ureters due to some obvious obstruction in the ureters.

Group 4. A normal bladder with dilatation of one or both ureters, but without obvious cause for the dilatation.

We have found no instance of a definitely hypertrophied bladder in which the ureters have been normal, nor an example in which, with a hypertrophied bladder, only one ureter has been dilated. Apparently when an obstruction arises of sufficient degree to produce hypertrophy of the bladder, both ureters soon become secondarily dilated.

Group 1.

Well recognised causes for this group, such as a vesical calculus or neoplasm, require no further explanation. These conditions in childhood do not commonly produce marked alterations in the urinary passages. There is, however, a specimen in the museum of the Hospital for Sick Children showing these results produced by a large vesical stone, and two similar examples resulting respectively from a myo-sarcoma and a papilloma of the bladder.

Other causes that have been cited as giving rise to obstruction to the passage of urine with secondary changes in the bladder, ureter and kidneys are congenital torsion of the penis, phimosis, atresia of the urethra, congenital hypertrophy of the veru montanum, cysts of the urethal mucosa and prostate, incomplete septa across the urethra, and valvular formations of the urethral mucosa. Valve formations have so far only been found in the male urethra and occur at the outlet of the bladder or in the posterior urethra.

Although many of the causes in this group are present at birth, in those cases that survive after birth symptoms may not appear for some months or years. The age of onset of symptoms is determined to some extent by the degree of obstruction, for obviously the most severe obstructions will tend to give rise to the earliest symptoms. In the milder cases puberty may be reached before the kidneys are sufficiently damaged for symptoms of chronic nephritis or uræmia to be manifest ; in others the symptoms of urinary infection may first appear and prove quickly fatal or else very resistant to treatment. 
Enuresis is a common symptom and is generally first noticed at the time when the normal child should be gaining control of the sphincters. The enuresis differs from the more common nocturnal type in that the urine flows uncontrolled during both day and night. These children might be expected to suffer from painful spasm of the bladder in attempting to overcome the obstruction, but symptoms of pain and distress from the distended bladder do not arise; nor has the bladder been palpated while undergoing active contractions, although the height of the bladder above the symphysis certainly varies from day to day from being just palpable to reaching as high as the umbilicus. In cases in which it is possible to pass a catheter and empty the bladder, examination a few hours later will generally show that the organ has again become over-distended.

The ureters not only dilate but increase in length and may become very tortuous; the renal pelves become dilated, although in our cases they could not be palpated ; the kidneys gradually undergo chronic interstitial inflammation and, as a result, the daily output of urine is excessive. The urine is pale and of low specific gravity. Eventually in most cases the urinary tract becomes infected with the bacillus coli producing cystitis and pyelitis, which in the fatal cases advances to suppurative pyelonephritis. In some of our cases the occurrence of pus in the urine has extended over several years. Case 2 has had pyuria for four years and is quite intractable to the ordinary lines of treatment. Death results from uræmia.

\section{Group 2.}

The symptoms of this group differ in no way from those of the preceding group except that the passage of a catheter should meet with no obstruction whereas in Group 1 it may be difficult or impossible to get a catheter as far as the bladder. In Case 7, the case with a valvular obstruction, the dilatation of the bladder was regarded as idiopathic until it was found impossible to get a catheter past the posterior urethra ; the presence of a septum or valve in the prostatic urethra was then suspected and anticipated at the post-mortem examination.

A study of this case with Case 6 may throw some light on the causation of some of those instances hitherto regarded as idiopathic. Had the presence of a valve in the urethra in Case 7 not been suspected before performing the autopsy, it is probable that the kidneys, ureters and bladder would have been removed en bloc, the urethra being divided somewhere across the prostatic portion. Owing to the direction of the valve, had a probe then been passed up from the glans penis towards the bladder, the end of the probe could easily have negotiated the valve and thus the cause of the condition would have been missed. It is important therefore when performing an autopsy on this type of case to remove the urethra in continuity with the bladder, a proceeding which is facilitated in children because the symphysis pubis can be divided and the two halves widely separated to make the dissection of the urethra easy. At the post mortem on Case 6, the urethra was divided at the distal end of the verumontanum and although a probe was passed along the penile urethra, in 
the light of the findings in Case 7, it is possible that some form of valvular obstruction may have been overlooked, or destroyed when the urethra was divided.

The passage of a probe along the urethra is generally taken as evidence that there is no obstruction, but it has been pointed out by previous writers that the free edge of a urethral valve formation is usually directed towards the bladder, and thus while egress of urine is prevented, a catheter or probe could pass up from the glans penis through the valve to the bladder. Moreover, the valve is composed of thin tissue which could easily be torn and destroyed if any slight force were used in passing a probe.

The only satisfactory way of proving an obstruction in the urethra post mortem is to remove the entire channel with the bladder. Even then unless the urethra is opened up cautiously a valve or incomplete septum may easily be severed; it would then be difficult to appreciate the precise nature of the obstruction. These difficulties are well illustrated by four specimens of idiopathic dilatation of the bladder and ureters in the museum of the Hospital for Sick Children. In all of these the bladder has been severed at its junction with the urethra. In two there is no record of the examination of the urethra, and in the other two (one from a female child) the urethra is stated to have admitted a large probe ; but as has been pointed out, this does not necessarily exclude the presence of some organic obstruction.

The secondary changes that occur in the bladder, ureters, and kidneys in the second group are identical with those in Group 1, and there can be no doubt that these changes result from some form of obstruction. From the evidence of the specimens at our disposal we cannot eliminate from this second idiopathic group the possibility that an obstruction has been overlooked. In view of the minutc examination required to discover such an obstruction as was present in Dr. Hutchison's case, and bearing in mind the anatomical similarity of the cases in Group 2 to those in Group 1, we are of opinion that there is no convincing evidence to enable us to set aside a mechanical explanation, which seems to fit the facts better than any other.

A study of the literature certainly indicates a group in which no obstruction has been discovered after death, and various theoretical explanations have been suggested to account for such cases.

They have been compared with hypertrophic pyloric stenosis. On anatomical grounds, we believe such a comparison is not strictly justifiable because in the majority of cases of idiopathic hypertrophy of the bladder the sphincter vesicæ has not been found hypertrophied out of proportion to the rest of the bladder as is the pyloric sphincter to the rest of the stomach ; indeed, it is usually found that the whole bladder is equally hypertrophied. A more suitable comparison has been drawn with congenital idiopathic dilatation of the colon, where part or the whole of the colon is thickened without special hypertrophy of its terminal portion. It still remains to explain the hypertrophy of the muscle. 
It has been suggested that in certain instances where hypertrophy of the bladder has been associated with spina bifida or spinal disease, a defect in the nervous mechanism of the bladder has resulted from the spinal deformity. It is, however, conceivable that we have in such cases two different congenital abnormalities existing in the same child, just as congenital morbus cordis and mongolism often occur together, and that the spina bifida bears no direct relationship to the hypertrophy of the bladder. In the absence of any gross malformation or disease of the spinal cord, it is possible that there might be a congenital maldevelopment of the nervous control of the detrusor and sphincter muscles of the bladder, resulting in an inco-ordination of their reciprocal functions, so that the normal contraction of one and the simultaneous relaxation of the other would be replaced by simultaneous contraction or relaxation of both groups of muscles. Such a disharmony might lead to hypertrophy of the whole bladder.

The thickness of the bladder has been regarded in some instances as due to a primary developmental hyperplasia of the muscle ; but provided that the nervous control of this muscle is unimpaired, the mere fact of hyperplasia should not produce obstruction and incontinence.

The urine in our cases has been of low specific gravity and free of mucus, and could of itself offer no obstruction. Excess of mucus in the bladder has been described and brought forward as a possible cause of obstruction. At the post-mortem examination on two of our cases there was an intense hæmorrhagic cystitis, but no increase of mucus was noticed in the bladder.

Group 3.

The symptoms and morbid anatomy of this group bear scarcely any relation to those of the preceding groups. Many instances such as Case 8 show no symptoms during life to point to disease of the urinary system, and the condition is revealed unexpectedly at post-mortem examination. In others a bacillus coli infection occurs in the kidney, and if the patient survives for any length of time, the persistence of pyuria in spite of continuous treatment arouses suspicion that the case is more than a simple pyelitis. The need for examination with the cystoscope and investigation by means of pyelography become essential if the true state of these cases is to be elucidated. Even these means may fail in instances such as Case 8 , where it would have been impossible to catheterise the stenosed lower end of the left ureter.

Dilatation of one ureter may be due to impaction of a calculus in the lower end of the ureter, or may result from a new growth. In the museum of the Children's Hospital are two specimens showing considerable dilatation of a ureter by impaction of a calculus. Other causes for obstruction consist of twists and kinks of the ureter, produced in some cases by aberrant renal vessels. Portions of the ureter may be severely narrowed, or the canal actually obliterated in part of its course. 
Figure 9 shows a condition exactly analogous to Case 8 , in which the left ureter is very dilated from stenosis of its terminal half inch. In Figures 8 and 9 the stenosed portion is obvious, but at the post mortem on these cases, the cause of the dilatation was obscured because the dilated ureter was adherent to the bladder and completely hid the terminal narrow canal; the stenosis extended down to but not through the bladder wall, so that the ureteric orifice into the bladder appeared normal. A complete dissection of the parts was necessary before the precise nature of the obstruction became apparent.
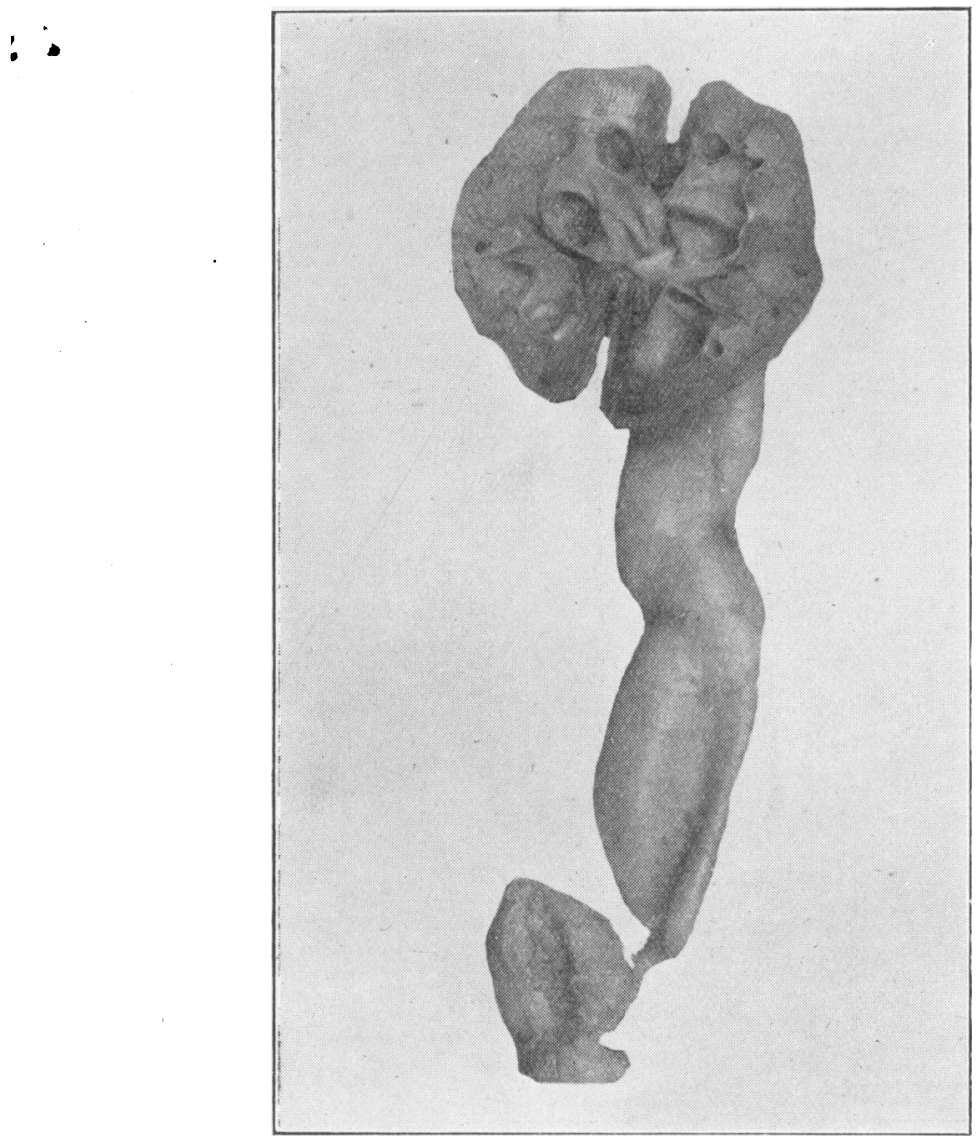

Fig. 9. A photograph of a specimen from the Museum of the Hospital for Sick Children, showing a condition of the left ureter precisely analogous to C ise 8 . The normal right ureter has been removed.

Such malformations are usually unilateral. Dilatation of both ureters due to some congenital abnormality in them must be very uncommon, but we have had one specimen in which both ureters were dilated to the size of intestine, although the bladder was normal. Further examination showed that the lumen. 
of both ureters at their lower end was very small, barely admitting a fine probe, and it is probable that the dilatation resulted from a bilateral stenosis of the ureters.

A curious association with dilatation of the ureters is that of horseshoe kidney, of which we have found three examples. In two, the left ureter only was enlarged; and in one of these the post-mortem record states that the lower end of the ureter was very narrow, only admitting a fine bristle. Figure 10 is a photograph of this specimen. In the third example, "both ureters were

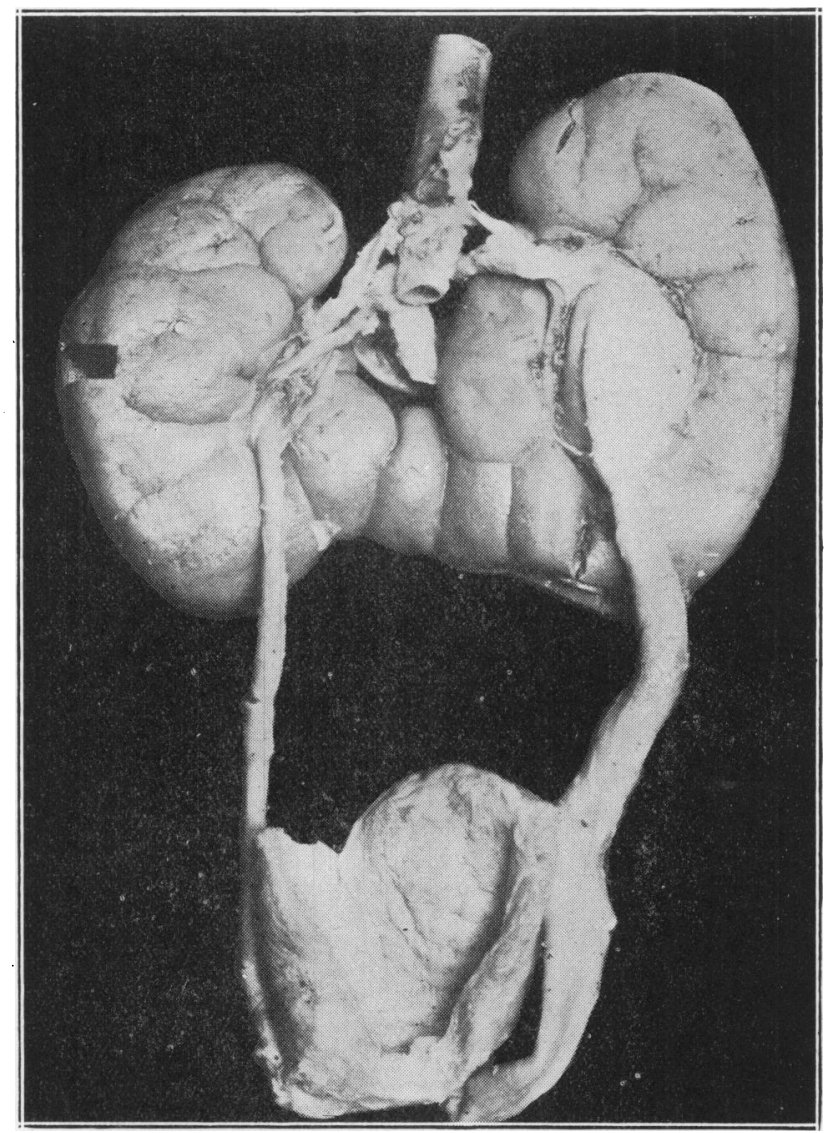

Fig. 10. A photograph of a specimen from the Museum of the Hospital for Sick Children, to show the association of horseshoe kidney with dilacation of the ureters. In this specimen, the left ureter only was dilated.

dilated resembling small intestine, and considerable pressure was required to force urine into the bladder." There can be no direct relation between horseshoe kidney and stenosis of the ureters, the association of the two conditions seems to be another instance of two congenital abnormalities existing in the same child. 
Group 4.

In all the specimens of dilatation of one or both ureters in conjunction with a normal bladder that we have examined, there has been some form of congenital or acquired organic obstruction sufficient to account for the dilatation. Cases of megalo-ureter are recorded in the literature in which no organic obstruction has been found. In one such instance, recorded by Grant, a girl, aged 18 months, had had for three months a heavy deposit of pus in the urine. Pyelography showed both ureters sausage shaped, the dilatation extending to the renal pelves; the bladder was normal and the ureteric orifices were patulous so that there was no discernable obstruction. The dilatation was considered to be secondary to infection which had in some way lowered the tone of the ureteric muscle. Treatment by irrigation of the bladder was performed four times a day for three months, by which time the ureters had become much smaller and their orifices practically normal.

Other instances have been explained on an embryological basis. It has been shown that between the fourth and fifth month of intrauterine development the ureters are of relatively large calibre, and a persistence of this after birth would result in a congenital megalo-ureter. A primary hypoplasia of the muscle of the ureter would aid in a persistence of the fœtal proportions, but in the dilated ureters which we have examined microscopically there has been no evidence of hypoplasia, the amount of muscle has been in excess of the normal.

The view that abnormal development of the nervous control of the ureters may take place in some cases, with the production of spasm of a segment of the ureter, the portion above eventually undergoing a secondary dilatation, lacks any convincing proof.

\section{Conclusion.}

Our conclusion from this investigation is that we believe there is in most of these cases of dilatation of the bladder and ureters in children a definite organic obstruction rather than a primary disturbance of function.

\section{REFERENCES.}

1. Hinman, F., and Kutzmann, J. Crology, Baltimore, 1925 XIV, 71.

These authors give reference to 50 cases of valvular obstruction in the urethra collected from the literature.

2. Bottomley, J. T., Annals Surgery, Philad., 1910, LII, 597.

The author gives references to 56 cases of stricture of the ureter collected from the literature. The references in these two articles have been omitted here.

The following articles have also been utilised in the preparation of this paper:-

3. Abt, I. A., Amer. J. Dis. Child., (hic., 1926, XXXII, 507.

4. Beer, E., J. Amer. Merl. Ass., Chic., 1915, LXV, 1709.

5. Beer, E., Annals Surgery, Philad., 1924, LXXIX, 264.

6. Box, C. R., Proc. Roy. Sor. Med., Lond., 1908-09, II (Path. Sect.), 134.

7. Box, C. R., Proc. Roy. Soc. Med., Lond., 1913-14, VII (Clin. Sect.), 70.

8. Braasch, W. F., J. Amer. Med. Ass., Chic., 1919, LXXIII, 731.

9. Brickdale, J. M. F., Rep. Soc. Study. Dis. Child., Lond., 1904, IV, 94.

10. Bryant, J. H., and White, W. H., Guy's Hosp. Rep., Lond., 1901, LV, 17.

11. Bumpus, H. C., J. Vrology, Baltimore, 1925, XIII, 551. 
12. Chute, A. L., ibid., 1921, V, 317.

13. Corsy, F., J. d'urol. méd et chir., Paris, 1920, IX, 185.

14. Eisendrath, D. N., Surg. Clin. N. America, Chic., 1925, IV, 635.

15. Eisenstadt, J. S., J. Urology, Baltimore, 1926, XV, 21.

16. Fordyce, A. D., and Capon, N. B., Brit. Journ. Child. Dis., Lond., 1924, XXI, 1.

17. Grant, O., J. Urology, Baltimore, 1926, XVI, 137.

18. Helmholz, H. F., Amer. J. Dis. Child., Chic., 1926, XXXII, 682.

19. Hepburn, T. N., Annals Surgery, Philadelphia, 1925, LXXXI, 1133.

20. Johnstone, R. W., and Browne, F. J., Edin. Med. J., 1921, I, 369.

21. Kahn, -, Med. Rec., N.Y., 1912, LXXXII, 895.

22. Keyes, E. L., J. Urology, Baltimore, 1925, XIV, 553.

23. Kirkpatrick, H., and Bradfield, E. W. C., Lancet, Lond., 1913, ii, 799.

24. Kohlbry, C. O., Amer. J. Dis. Child., Chic., 1923, XXVI, 242.

25. Kretschmer, H. L., Surg. Gyncecol. and Obstet., Chic., 1925, XLI, 713.

26. Lakin, C. E., Trans. Med. Soc., Lond., 1920, XLIII, 91.

27. Lansdowne, L. P., and Boyd, W., Can. Med. Ass. J., Montreal, 1925, XV, 361.

28. Lowsley, and Butterfield, J. Urology, Baltimore, 1926, XVI, 415.

29. Morris, H., Surgical Diseases of the Kidney and Ureter, Lond., 1901, 438, et seq.

30. Ockerblad, N. F., J. Urology, Baltimore, 1925, XIII, 329.

31. Parmenter, F. J., and Leutenegger, C., Amer. J. Dis. Child., Chic., 1926, XX XII, 692.

32. Robinson, W. W., J. Urology, Baltimore, 1927, XVII, 381.

33. Schultz, W. G., South West. Med. Phœnix, Arizona, 1925, IX, 352.

34. Shattock, S. G., Proc. Roy. Soc. Med., Lond., 1909, II (Path. Sect.), 88.

35. Simons, I., J. Urology, Baltimore, 1926, XV, 29.

36. Spencer, W. G., Westminster Hosp. Rep., Lond., 1901, XII, 94.

37. Spohr, J., Hospitalstid, Copenhagen, 1926, LXIX, 717.

38. Tattersall, S. R., Lancet, Lond., 1921, i, 534.

39. Williams, D., Trans. Path. Soc., Lond., 1888 XXXIX, 152. 